\title{
Safety and Efficacy of a Mouth-Rinse with Granulocyte Colony Stimulating Factor in Patients with Chemotherapy-Induced Oral Mucositis
}

\author{
Lin Wang ${ }^{\star}$, Xin-En Huang ${ }^{\AA *}$, Zhu-Qing Ji, Meng-Yan Liu, Ting Qian, Li Li
}

\begin{abstract}
Objective: To assess the safety and effectiveness of a mouth-rinse with G-CSF (JiSaiXin, produced by NCPC Biotechnology Co., Ltd) in treating patients with chemotherapy-induced oral mucositis (CIM). Method: A consecutive cohort of patients with advanced cancers and CIM were treated with mouth-rinse G-CSF. All chemotherapy for patients with advanced cancers was adopted from regimens suggested by NCCN guidelines. The mouth-rinse with G-CSF at a dose of $150-300$ ug plus $100 \mathrm{ml}-500 \mathrm{ml}$ normal saline was started from the time of oral mucositis was confirmed and continuously used for at least 7 days as one course. After at least two courses of treatment, safety and efficacy were evaluated. Results: There were 7 female and 7 male patients with advanced cancer and CIM recruited into this study, including 5 with colorectal, 2 with lung, 1 patient with gastric, 1 with cervical and 1 with pancreatic cancer, as well as 2 patients with diffuse large $B$ cell lymphomas, 1 with nasopharyngeal and 1 with gastric cancer. The median age was 57 (41-79) years. Grade 1 to 2 myelosuppression was observed in 3/14 patients, and Grade 4 myelosuppression in 1/14. Adverse effects on the gastrointestinal tract were documented in 5/14 patients, and were Grade 1 to Grade 3. No treatment related death was documented. Regarding CIM, the median response time to mouth rinse of G-CSF was 2 (1-5) days, and all patients with CIM demonstrated a positive response. Conclusions: Mouth-rinse with G-CSF proved to be safe and effective in treating patients with advanced cancers and CIM. However, further randomized controlled studies should be conducted to clarify the effectiveness of this treatment with other lesions.
\end{abstract}

Keywords: Mouth-rinse with G-CSF - chemotherapy induced oral mucositis

Asian Pac J Cancer Prev, 17 (1), 413-418

\section{Introduction}

One common side effect of chemotherapy is oral mucositis with an occurrence rate of 40-100\%, depending on the type of cancer, chemotherapeutic medications, age of patient, neutrophil count, and availability of oral care (Raber-Durlacher et al., 2000; Mosel et al., 2011).

Cancer patients first reported symptoms of chemotherapy-induced mucositis (CIM) and diagnosed with CIM usually within 3-5 days after initiation of chemotherapy, and the symptom of CIM could reach a peak within 7-14 days. The course of CIM usually could last nearly 3 weeks (Loprinzi et al., 1999). CIM is associated with serials of complications, eg., oral pain, that will adversely affect nutrition, speaking, function and quality of life of patients. CIM is also linked with susceptibility to septicemia especially in conditions of neutrocytopenia. Thus, CIM could consequently result in hospitalization, increased treatment cost and delayed optimal treatment due to restrictions on dosage of chemotherapeutic agents (Raber-Durlacher et al., 2000; Mosel et al., 2011).

A lot of medications have been attempted to treat CIM including basic oral care, eg., brushing, flossing, dental visits before and during the treatment and usage of mouth-washes, cryotherapy, as well as anti-inflammatory, antimicrobial and antiseptic agents, vitamins, cytokines, immune regulator, herbal medicine, etc (McGuire et al., 2013; Nicolatou-Galitis et al., 2013; Raber-Durlacher et al., 2013; Saunders et al., 2013).

Granulocyte colony-stimulating factor (G-CSF) is a cytokines used as hematopoietic growth factor that could stimulate the development of granulocyte (Plevova et al., 1999). G-CSF has been shown to promote wound healing in animal studies (Jyung et al., 1994). However, clinical studies on the effectiveness of mouth rinse medication when treating patients with CIM who received standard or high dose chemotherapy are mainly focused on GM-CSF 
(Dazzi et al., 2003; van der Lelie et al., 2001; Cartee et al., 1995). In a recent study on the effectiveness of GMCSF in reducing occurrence of oral mucositis, (Dazzi et al., 2003), patients were instructed to rinse for $1 \mathrm{~min}$ with $150 \mu \mathrm{g} /$ day of GM-CSF in $100 \mathrm{~cm} 3$ of sterile water in four doses per day. Furthermore, patients in both treatment and control groups received conventional prophylaxis with chlorhexidine $0.2 \%$ mouth rinse and amphotericin B (Dazzi et al., 2003). The result of this study suggested that prophylaxis with GM-CSF mouth wash could not help to reduce the severity of mucositis in the setting of this study (Dazzi et al., 2003).

According to this background, it is obvious that insufficient studies were conducted to investigate the treatment effect of G-CSF for patients with CIM. We hypothesize that mouth-rinse with G-CSF could be an effective medication in treating cancer patients with CIM.

\section{Materials and Methods}

\section{Eligibility criteria}

Patients: Patients recruited in this study were required to be pathologically/ cytologically diagnosed with cancer in Jiangsu Cancer Hospital \& Research Institute; to sign an informed consent before treatment; to expose to long term chemotherapy and supportive care, and were diagnosed with oral mucositis; to have a score of Karnofsky Performance Status (KPS) $\geq 60$ with expectancy life span more than 3 moths; to be classified with no contraindications for chemotherapy; to have a routine blood test and oral examination performed 0 to 3 days before and after chemotherapy, and normal hematopoietic function as evidenced by white blood cell count 3000/ul and platelet count 100000/ul, normal hepatic function test (aspartate aminotransaminase and alanine aminotransferase less than 1.5 times of the upper limit of normal values), renal function test (serum total bilirubin $<1.5 \mathrm{mg} / \mathrm{dl}$ and creatinine $<1.5 \mathrm{mg} / \mathrm{dl}$ ). Exclusion criteria included history of alcoholic intoxication, diabetes, and patients who were pregnant or nursing. Chemotherapy was administered according to NCCN guideline. Mouth-rinse with G-CSF (JiSaiXin, produced by NCPC
Biotechnology CO., LTD) at a dosage of 150-300ug plus $100 \mathrm{ml}-500 \mathrm{ml}$ normal saline was started from the time of oral mucositis was confirmed and continuously used for at least 7 days as one course. After at least two courses of treatment, safety and effectiveness were evaluated. We have enough experience in conducting medical researches, and have published some results elsewhere (Chen et al., 2014; Chen et al., 2014; Cao et al., 2014; Cui et al., 2014; Huang et al., 2014; Huang et al., 2014; Ji et al., 2014; Liu et al., 2014; Liu et al., 2014; Lu et al., 2014; Qian et al., Tian et al., 2014; 2014; Xiao et al., 2014; Xiao et al., 2014; Xu et al., 2014; Xu et al., 2014; Xu et al., 2014; Xu et al., 2014; Wang et al., 2014; Wu et al., 2014; Cui et al., 2015; Huang et al., 2015; Huang et al., 2015; Li et al., 2015; Liu et al., 2015; Liu et al., 2015; Qian et al., 2015; Shen et al., 2015; Shi et al., 2015; Sun et al., 2015; Xu et al., 2015; Xu et al., 2015; Xu et al., 2015; Xu et al., 2015; Wang et al., 2015; Wu et al., 2015; Wu et al., 2015; Yang et al., 2015; Zhou et al., 2015)

\section{Toxicity Evaluation}

The incidence rates of toxicity in this study were assessed at baseline and respectively after two cycles of treatment, the grade of toxicities was determined according to The National Cancer Institute Common Terminology Criteria for Adverse Events (NCI CTCAE; version 3).

\section{Results}

There were 7 female and 7 male patients with advanced cancer recruited into this study, including 5 patients with colorectal, 2 patients with lung, 1 patient with gastric, 1 patient with cervical and 1 patient with pancreatic cancer, as well as 2 patients with diffuse large B cell lymphoma, 1 patient with nasopharyngeal and 1 patient with gastric cancer (Table 1). The median age of patients was 57 (41-79) years. Incidences of Grade 1 to 2 myelosuppression was observed in 3/14 patients, and Grade 4 myelosuppression was observed in 1/14 patient. Adverse effects on the gastrointestinal tract were documented in 5/14 patients, and were Grade 1 to Grade 3. No treatment related death

Table 1. Characteristics of Recruited Patients

\begin{tabular}{|c|c|c|c|c|c|c|}
\hline $\begin{array}{l}\text { Hospital } \\
\text { registration } \\
\text { number }\end{array}$ & $\begin{array}{l}\text { Gender } \\
\text { (Male/Femal }\end{array}$ & $\begin{array}{l}\text { Age(year) } \\
\text { le) }\end{array}$ & Diagnosis & $\begin{array}{l}\text { Stage of } \\
\text { disease }\end{array}$ & $\begin{array}{r}\text { Duratio } \\
\text { with }\end{array}$ & $\begin{array}{l}\text { ion of response } \\
\text { to mouth rinse } \\
\text { ith G-CSF (days) }\end{array}$ \\
\hline 266241 & Female & 61 & Pancreatic cancer & IV & FOLFOXIRI & 3 \\
\hline 265135 & Male & 52 & Colon cancer & Dukes C & FOLFOX & 2 \\
\hline 262901 & Male & 57 & Rectal caner & Dukes C & FOLFOX & 2 \\
\hline 250674 & Female & 52 & Lung ademocarcinoma & IV & Pemtrexed+Docetaxel+Oxaliplatin & in \\
\hline 265320 & Male & 77 & Colon cancer & IV & FOLFOX & 2 \\
\hline 265587 & Male & 41 & Gastric cancer & IV & Docetaxel+Oxaliplatin+TS-1 & 2 \\
\hline 266345 & Female & 58 & Diffuse large B cell lymphoma & II & CHOP & 3 \\
\hline 195410 & Female & 62 & Colon cancer & IV & FOLFOXIRI & 1 \\
\hline 265863 & Male & 46 & Small cell lung cancer & limited & CPT-11+Nedaplatin & 4 \\
\hline 243887 & Female & 79 & Colon cancer & IV & FOLFOX & 2 \\
\hline 194256 & Female & 54 & Cervical cancer & IV & Paclitaxel+Nedaplatin+5-Fu+CF & 1 \\
\hline 210374 & Male & 62 & Diffuse large B cell lymphoma & III & ECHOP & 3 \\
\hline 267091 & Male & 58 & Head and neck cancer & IV & Paclitaxel+Nedaplatin+TS-1 & 4 \\
\hline 179540 & Female & 48 & Nasopharyngeal cancer & IV & Paclitaxel+Nedaplatin & 5 \\
\hline
\end{tabular}


was documented. Regarding oral mucositis, the median response time to mouth rinse of G-CSF was 2 (1-5) days, and all patients with CIM response to mouth rinse with G-CSF (response rate $=100 \%$ ).

\section{Discussion}

Cancer is a group of diseases with deregulated growth of abnormal cells. The reason for this uncontrolled growth is a series of mutations that cause aberrant expression of gene products essential for regulating proliferation, survival, and growth activities of cells; and further, cause basic biological changes of cells: the ability to respond to growth signals, engage cell death programs to eliminate unnecessary, excess or damaged cells, and the formation of new blood vessels and ability to invade tissue. Thus, clinicians and researchers try to find effective therapeutic approaches that could eliminate cancerous cells, meanwhile protecting normal, healthy tissues. In the field of current cancer treatment $\square$ chemo-, or radiation therapy, is one of the most commonly used methods. However, one important problem of chemo-, or radiation therapy is that these treatments are associated with various toxicities, including CIM (Kalyanaraman B et al., 2002; Naumov GN et al., 2003).

Regarding the treatment for CIM, oral care is considered as essential for cancer patients with CIM. A meta-analysis performed by Stokman et al. concluded that systemic $\mathrm{G}(\mathrm{M})$-CSF might prevent oral mucositis (Stokmanet al., 2006). Previous studies suggested evidence of GM-CSF mouthwash for the prevention of oral mucositis is controversial (Dazzi et al., 2003 ; Nicolatou-Galitis et al., 2013). A clinical study by using GM-CSF mouthwashes to treat patients with CIM in metastatic breast cancer found no clear benefit (Cartee et al., 1995). And further, evidence from randomized controlled study suggested that GM-CSF mouth washes are not effective to prevent oral mucositis (van der Lelie et al., 2001). However, there are also evidences from case series suggesting effectiveness of GM-CSF mouth washes on mucositis in patients with head and neck cancer (Nicolatou et al., 1998; Nicolatou-Galitis et al., 2001), and were verified by other studies (Saarilahti et al., 2002; Mantovani et al., 2003). Several studies addressed the use of GM-CSF mouth washes for the treatment of established mucositis in patients receiving chemo- radiotherapy for head and neck tumors, HSCT and chemotherapy (Rovirosa et al., 1998; Mantovani et al., 2003; Ibrahim et al., 1997; Hejna et al., 2001; Bez et al., 1999; Valcarcel et al., 2002; ). Thus, it was supposed that GM-CSF mouth rinses could be used for prevention and treatment for patients with chemotherapy. On the other side, systemically infused GM-CSF was also tested for patients with CIM. One study reported a benefit from systemically infused GM-CSF in treating patients with head and neck cancer and CIM (Chi et al., 1995; Kannan et al., 1997 ; Rosso et al., 1997; Wagner et al., 1999; McAleese et al., 2006), however was not confirmed by others (Ryu et al., 2007; Makkonen et al., 2000). Therefore, it was suggested that systemic infusion of GM-CSF at present should not be recommended for patients with CIM.
In terms of G-CSF, according to previous researches, it is not suggested that the use of subcutaneous G-CSF is able to prevent oral mucositis in head and neck cancers patients treated with chemo-, or radiotherapy (Abitbol et al., 1997; Mascarin et al., 1999). Only one study on the use of systemic

G-CSF for the prevention of CIM for head and neck cancers has been published (Su et al., 2006). This study reported a non-significant trend for a beneficial effect of this intervention but was closed prematurely because of low accrual. Worthington et al. concluded that there is weak evidence that systemic or topical G-CSF may be beneficial for the prevention of severe oral mucositis in head and neck cancer patients undergoing radiotherapy (Worthington et al., 2010). Thus, it was concluded that no guideline could be provided for the use of subcutaneous G-CSF for the prevention of CIM (Katano et al., 1995 ; Viens et al., 1996). In addition, no guideline could be provided for the use of a G-CSF mouthwash for the prevention of CIM (Karthaus et al., 1998).

In this study, our purpose is to assess the safety and effectiveness of mouth-rinse with G-CSF (JiSaiXin, produced by NCPC Biotechnology CO., LTD) in treating patients with CIM. We recruited 7 female and 7 male patients with advanced cancer into this study, including 5 patients with colorectal, 2 patients with lung, 1 patient with gastric, 1 patient with cervical and 1 patient with pancreatic cancer, as well as 2 patients with diffuse large B cell lymphoma, 1 patient with nasopharyngeal and 1 patient with gastric cancer. The median age of patients was 57 (41-79) years. Mouth-rinse with G-CSF was started at a dosage of $150-300 u g$ plus $100 \mathrm{ml}-500 \mathrm{ml}$ normal saline from the time of oral mucositis and was confirmed and continuously used for 7 days as one course. As a result, it was suggested that the incidence of Grade 1 to 2 myelosuppression was observed in $3 / 14$ patients, and Grade 4 myelosuppression was observed in $1 / 14$ patient. Adverse effects on the gastrointestinal tract were documented in 5/14 patients, and were Grade 1 to Grade 3. No treatment related death was documented. In terms of oral mucositis, the median response time to mouth rinse of G-CSF was 2 (1-5) days, and the response rate of mouth rinse of G-CSF was $100 \%$. In conclusion, our current study suggested that mouth-rinse with G-CSF combined with chemotherapy was safe and effective in treating advanced cancers patients with CIM. However, further randomized controlled studies should be conducted to clarify the effectiveness of this treatment with others.

\section{Acknowledgements}

Dr. Xin-En Huang is supported by Traditional Chinese Medicine Scientifi Research Project (LZ11091) and Jiangsu Province fourth stage "333 high- level Personnel Training Project" third levels of talent cultivating object.

\section{References}

Abitbol AA, Sridhar KS, Lewin AA, et al (1997). Hyperfractionated radiation therapy and 5-fluorouracil, cisplatin, and mitomycin-C (+/- granulocyte-colony 
stimulating factor) in the treatment of patients with locally advanced head and neck carcinoma. Cancer, 80, 266-76.

Bez C, Demarosi F, Sardella A, et al (1999). GM-CSF mouthrinses in the treatment of severe oral mucositis: a pilot study. Oral Surg Oral Med Oral Pathol Oral Radiol Endod, 88, 311-5

Cao J, Huang XE, Liu J, et al (2014). Comparison of efficacy and toxicity of first line chemotherapy with or without epirubicin for patients with advanced stage soft tissue sarcoma. Asian Pac J Cancer Prev, 14, 7171-7.

Cartee L, Petros WP, Rosner GL, et al (1995). Evaluation of GMCSF mouthwash for prevention of chemotherapy-induced mucositis: a randomized, double-blind, dose-ranging study. Cytokine, 7, 471-7.

chemotherapy-induced oral mucositis. Surg Today, 25, 202-6.

Chen YS, Xu SX, Ding YB, et al (2014). Colorectal cancer screening in high-risk populations: a survey of cognition among medical professionals in Jiangsu, China. Asian Pac $J$ Cancer Prev, 14, 6487-91.

Chen YS, Xu SX, Ding YB, et al (2014). Helicobacter pylori Infection and the risk of colorectal adenoma and adenocarcinoma: an updated meta-analysis of different testing methods. Asian Pac J Cancer Prev, 14, 7613-9.

Chi KH, Chen CH, Chan WK, et al (1995). Effect of granulocytemacrophage colony-stimulating factor on oral mucositis in head and neck cancer patients after cisplatin, fluorouracil, and leucovorin chemotherapy. J Clin Oncol, 13, 2620-8.

Cui L, Liu XX, Jiang Y, et al (2014). Phase II study on dose escalating schedule of paclitaxel concurrent with radiotherapy in treating patients with locally advanced non-small cell lung cancer. Asian Pac J Cancer Prev, 15 , 1699-702.

Cui L, Sun YH, Chen J, et al (2015). Analysis of Prethrombotic States in Patients with Malignant Tumors. Asian Pac J Cancer Prev, 16, 5477-82.

Dazzi C, Cariello A, Giovanis P, et al (2003). Prophylaxis with GM-CSF mouthwashes does not reduce frequency and duration of severe oral mucositis in patients with solid tumors undergoing high-dose chemotherapy with autologous peripheral blood stem cell transplantation rescue: a double blind, randomized, placebo-controlled study. Ann Oncol, 14, 559-63.

Hejna M, Kostler WJ, Raderer M, et al (2001). Decrease of duration and symptoms in chemotherapy-induced oral mucositis by topical GM-CSF: results of a prospective randomised trial. Eur J Cancer, 37, 1994-2002

Huang XE, Cao J, Qian ZY, et al (2014). Leucogen tablets at $60 \mathrm{mg}$ three times per day are safe and effective to control febrile neutropenia. Asian Pac J Cancer Prev, 15, 8495-7.

Huang XE, Tian GY, Cao J, et al (2014). Pemetrexed as a component of first-, second- and third- line chemotherapy in treating patients with metastatic lung adenocarcinoma. Asian Pac J Cancer Prev, 14, 6663-7.

Huang XE, Wang L, Ji ZQ, et al (2015). Safety of Lienal Polypeptide Injection Combined with Chemotherapy in Treating Patients with Advanced Cancer. Asian Pac J Cancer Prev, 16, 7837-41.

Huang XE, Yan XC, Wang L, et al (2015). Thalidomide Combined with Chemotherapy in Treating Patients with Advanced Colorectal Cancer. Asian Pac J Cancer Prev, 16, 7867-9.

Ibrahim EM, al-Mulhim FA (1997). Effect of granulocytemacrophage colony-stimulating factor on chemotherapy-induced oral mucositis in non-neutropenic cancer patients. Med Oncol, 14, 47-51

Ji ZQ, Huang XE, Wu XY, et al (2014). Safety of Brucea javanica and cantharidin combined with chemotherapy for treatment of NSCLC patients. Asian Pac J Cancer Prev, 15, 8603-5.

Jyung RW, Wu L, Pierce GF, et al (1994). Granulocytemacrophage colony-stimulating factor and granulocyte colony-stimulating factor: differential action on incisional wound healing. Surgery, 115, 325-34.

Kalyanaraman B, Joseph J, Kalivendi S, et al (2002). Doxorubicininduced apoptosis: implications in cardiotoxicity. Mol Cell Biochem, 234-5, 119-24.

Kannan V, Bapsy PP, Anantha N, et al (1997). Efficacy and safety of granulocyte macrophage-colony stimulating factor (GM$\mathrm{CSF}$ ) on the frequency and severity of radiation mucositis in patients with head and neck carcinoma. Int J Radiat Oncol Biol Phys, 37, 1005-10.

Karthaus M, Rosenthal C, Huebner G, et al (1998). Effect of topical oral G-CSF on oral mucositis: a randomised placebocontrolled trial. Bone Marrow Transplant, 22, 781-785

Katano M, Nakamura M, Matsuo T, et al (1995)..Effect of granulocyte colony-stimulating factor (G-CSF) on

Li Y, Huang XE (2015). A Pooled Analysis on Crizotinib in Treating Chinese Patients with EML4-ALK Positive Nonsmall-cell Lung Cancer. Asian Pac J Cancer Prev, 16, 4797-800.

Liu J, Huang XE (2015). Clinical application of serum tumor abnormal protein from patients with gastric cancer. Asian Pac J Cancer Prev, 16, 4041-4.

Liu J, Huang XE 1 (2014). Efficacy of Bifidobacterium tetragenous viable bacteria tablets for cancer patients with functional constipation. Asian Pac J Cancer Prev, 15, 10241-4.

Liu J, Huang XE, Feng JF (2014). Further study on pemetrexed based chemotherapy in treating patients with advanced gastric cancer (AGC). Asian Pac J Cancer Prev, 15, 6587-90.

Liu MY, Huang XE (2015). Effects of analgecine on oxaliplatininduced neurotoxicity in patients with gastrointestinal cancer. Asian Pac J Cancer Prev, 16, 4465-8.

Loprinzi C, Gastineau D, Foote R (1995). Oral complications Clinical Oncology . New York: Churchill Livingstone, pp. 741-54.

Lu YY, Huang XE, Wu XY, et al (2014). Clinical observations on associations between the UGT1A1 genotype and severe toxicity of irinotecan. Asian Pac J Cancer Prev, 15, 3335-41.

Makkonen TA, Minn H, Jekunen A, et al (2000). Granulocyte macrophage-colony stimulating factor (GM-CSF) and sucralfate in prevention of radiation-induced mucositis: a prospective randomized study. Int J Radiat Oncol Biol Phys, 46, 525-534.

Mantovani G, Massa E, Astara G, et al (2003). Phase II clinical trial of local use of GM-CSF for prevention and treatment of chemotherapy- and concomitant chemoradiotherapyinduced severe oral mucositis in advanced head and neck cancer patients: an evaluation of effectiveness, safety and costs. Oncol Rep, 10, 197-206

Mascarin M, Franchin G, Minatel E, et al (1999). The effect of granulocyte colonystimulating factor on oral mucositis in head and neck cancer patients treated with hyperfractionated radiotherapy. Oral Oncol, 35, 203-208.

McAleese JJ, Bishop KM, A'Hern R, et al (2006). Randomized phase II study of GM-CSF to reduce mucositis caused by accelerated radiotherapy of laryngeal cancer. $\mathrm{Br} J$ Radiol, 79, 608-13

McGuire DB, Fulton JS, Park J, et al (2013). Systematic review of basic oral care for the management of oral mucositis in cancer patients. Supportive Care in Cancer, 21, 3165-77.

Mosel D, Bauer R, Lynch D, et al (2011). Oral complications in the treatment of cancer patients. Oral Dis, 17, 550-9.

Naumov GN, Townson JL, MacDonald IC, et al (2003). Ineffectiveness of doxorubicin treatment on solitary dormant 
mammary carcinoma cells or late-developing metastases. Breast Cancer Res Treat, 82, 199-206.

Nicolatou O, Sotiropoulou-Lontou A, Skarlatos J, et al (1998). A pilot study of the effect of granulocyte-macrophage colonystimulating factor on oral mucositis in head and neck cancer patients during X-radiation therapy: a preliminary report. Int J Radiat Oncol Biol Phys, 42, 551-6

Nicolatou-Galitis O, Dardoufas K, Markoulatos P, et al (2001). Oral pseudomembranous candidiasis, herpes simplex virus-1 infection, and oral mucositis in head and neck cancer patients receiving radiotherapy and granulocyte-macrophage colonystimulating factor (GM-CSF) mouthwash. J Oral Pathol Med, 8, 471-80.

Nicolatou-Galitis O, Sarri T, Bowen J, et al (2013). Systematic review of anti-inflammatory agents for the management of oral mucositis in cancer patients. Supportive Care in Cancer, 21, 3179-89.

Patte C, Laplanche A, Bertozzi AI, et al (2002). Granulocyte colony-stimulating factor in induction treatment of children with non-Hodgkin's lymphoma: a randomized study of the French Society of Pediatric Oncology. J Clin Oncol, 20, 441-448.

Plevova P (1999). Prevention and treatment of chemotherapyand radiotherapy-induced oral mucositis: a review. Oral Oncol, 35, 453-70.

Qian T, Huang XE (2015). Study of Pemetrexed-based Chemotherapy for Patients with Locally Advanced or Metastatic Cancers. Asian Pac J Cancer Prev, 16, 4791-5.

Qian YD, Xu X, Wang L, Huang XE (2014). Clinical safety of chemotherapy for elderly cancer patients complicated with hypertension. Asian Pac J Cancer Prev, 15, 9875-7.

Raber-Durlacher J, Weijl N, Saris MA, et al (2000). Oral mucositis in patients treated with chemotherapy for solid tumors: a retrospective analysis of 150 cases. Support Care Cancer, 8, 366-71.

Raber-Durlacher JE, von Bültzingslöwen I, Logan RM, et al (2013). Systematic review of cytokines and growth factors for the management of oral mucositis in cancer patients. Support Care Cancer, 21, 343-55.

Rosso M, Blasi G, Gherlone E, et al (1997). Effect of granulocyte-macrophage colony-stimulating factor on prevention of mucositis in head and neck cancer patients treated with chemoradiotherapy. J Chemother, 9, 382-5.

Rovirosa A, Ferre J, Biete A (1998). Granulocyte macrophagecolony-stimulating factor mouthwashes heal oral ulcers during head and neck radiotherapy. Int $J$ Radiat Oncol Biol Phys, 41, 747-54.

Ryu JK, Swann S, LeVeque F, et al (2007). The impact of concurrent granulocyte macrophage-colony stimulating factor on radiation-induced mucositis in head and neck cancer patients: a double-blind placebo-controlled prospective phase III study by Radiation Therapy Oncology Group 9901. Int J Radiat Oncol Biol Phys, 67, 643-50.

Saarilahti K, Kajanti M, Joensuu T, et al (2002). Comparison of granulocyte-macrophage colony-stimulating factor and sucralfate mouthwashes in the prevention of radiationinduced mucositis: a double-blind prospective randomized phase III study. Int J Radiat Oncol Biol Phys, 54, 479-85

Saunders DP, Epstein JB, Elad S, et al (2013). Systematic review of antimicrobials, mucosal coating agents, anesthetics, and analgesics for the management of oral mucositis in cancer patients. Support Care Cancer, 21, 3191-207.

Schneider SB, Nishimura RD, Zimmerman RP, et al (1999). Filgrastim (rmetHuG-CSF) and its potential use in the reduction of radiationinduced oropharyngeal mucositis: an interim look at a randomized, double-blind, placebocontrolled trial. Cytokines Cell Mol Ther, 5, 175-80.
Shen K, Huang XE (2015). Clinical investigation in effect of riboflavin sodium phosphate on prevention and treatment for patients with radiotherapy related esophagitis. Asian Pac J Cancer Prev, 16, 1525-7.

Shi B, Zhang XB, Xu J, et al (2015). Systematic Analysis of Icotinib Treatment for Patients with Non-Small Cell Lung Cancer. Asian Pac J Cancer Prev, 16, 5521-4.

StokmanMA, Spijkervet FK, Boezen HM, et al (2006). Preventive intervention possibilities in radiotherapy- and chemotherapy-induced oral mucositis: results of metaanalyses. J Dent Res, 85, 690-700

Su YB, Vickers AJ, Zelefsky MJ, et al (2006). Double-blind, placebo-controlled, randomized trial of granulocyte-colony stimulating factor during postoperative radiotherapy for squamous head and neck cancer. Cancer J, 12, 182-8.

Sun YH, Cui L, Chen J, et al (2015). Analysis of Relationships Between Prethrombotic States and Cervical Cancer. Asian Pac J Cancer Prev, 16, 6163-6.

Tian GY, Miu M, Huang XE (2014). Systematic analysis of pemetrexed-based chemoradiotherapy for patients with locally advanced or metastatic esophageal cancer. Asian Pac J Cancer Prev, 15, 8475-8.

Valcarcel D, Sanz MA Jr, Sureda A, et al (2002). Mouth-washings with recombinant human granulocyte-macrophage colony stimulating factor (rhGM-CSF) do not improve grade III-IV oropharyngeal mucositis $(\mathrm{OM})$ in patients with hematological malignancies undergoing stem cell transplantation. Results of a randomized double-blind placebo-controlled study. Bone Marrow Transplant, 29, 783-7

van der Lelie H, Thomas BL, van Oers RH, et al (2001). Effect of locally applied GM-CSF on oral mucositis after stem cell transplantation: a prospective placebo-controlled doubleblind study. Ann Hematol, 80, 150-4

Viens P, Gravis G, Bladou F, et al (1996). Impact of recombinant human granulocyte colony stimulating factor on dose intensity and toxicity of three cycles of methotrexate, vinblastine, doxorubicin and cisplatin in patients with previously untreated urothelial bladder carcinoma. Eur Cytokine Netw, 7, 395-9.

Wagner W, Alfrink M, Haus U, et al (1999). Treatment of irradiation-induced mucositis with growth factors (rhGMCSF) in patients with head and neck cancer. Anticancer Res, 19, 799-803.

Wang L, Huang XE (2015). Clinical study on safety and efficacy of JiSaiXin (recombinant human granulocyte colony stimulating factor injection manufactured in China) for Chinese undergoing chemotherapy. Asian Pac J Cancer Prev, 16, 299-301.

Wang L, Huang XE, Cao J (2014). Clinical study on safety of cantharidin sodium and shenmai injection combined with chemotherapy in treating patients with breast cancer postoperatively. Asian Pac J Cancer Prev, 15, 5597-600.

Worthington HV, Clarkson JE, Bryan G, et al (2010). Interventions for preventing oral mucositis for patients with cancer receiving treatment. Cochrane Database Syst Rev (12): CD000978

Wu XY, Huang XE (2015). Clinical Application of Serum Tumor Abnormal Protein (TAP) in Colorectal Cancer Patients. Asian Pac J Cancer Prev, 16, 3425-8.

Wu XY, Huang XE (2015). Screening for patients with non-small cell lung cancer who could survive long term chemotherapy. Asian Pac J Cancer Prev, 16, 647-52.

Wu XY, Huang XE, Cao J, et al (2014). A predictive model for evaluating responsiveness to pemetrexed treatment in patients with advanced colorectal cancer. Asian Pac J Cancer Prev, 15, 5941-4.

Xiao Y, Liu J, Huang XE, et al (2014). Clinical study on 
fluvoxamine combined with oxycodone prolonged-release tablets in treating patients with moderate to severe cancer pain. Asian Pac J Cancer Prev, 15, 10445-9.

Xiao Y, Liu J, Liu YC, et al (2014). Phase II study on EANI combined with hydrochloride palonosetron for prevention of chemotherapy-induced nausea and vomiting following highly emetogenic chemotherapy. Asian Pac J Cancer Prev, 15, 3951-4.

Xu C, Huang XE, Lv PH, et al (2015). Radiofrequency Ablation in Treating Colorectal Cancer Patients with Liver Metastases. Asian Pac J Cancer Prev, 16, 8559-61.

Xu C, Huang XE, Wang SX, et al (2014). Drainage alone or combined with anti-tumor therapy for treatment of obstructive jaundice caused by recurrence and metastasis after primary tumor resection. Asian Pac J Cancer Prev, $\mathbf{1 5}, 2681-4$.

Xu C, Huang XE, Wang SX, et al (2015). Comparison of infection between internal-external and external percutaneous transhepatic biliary drainage in treating patients with malignant obstructive jaundice. Asian Pac J Cancer Prev, 16, 2543-6.

Xu C, Lv PH, Huang XE, et al (2014). Safety and efficacy of sequential transcatheter arterial chemoembolization and portal vein embolization prior to major hepatectomy for patients with HCC. Asian Pac J Cancer Prev, 15, 703-6.

Xu C, Lv PH, Huang XE, et al (2014). Analysis of different ways of drainage for obstructive jaundice caused by hilar cholangiocarcinoma. Asian Pac J Cancer Prev, 15, 5617-20.

Xu C, Lv PH, Huang XE, et al (2014). Internal-external percutaneous transhepatic biliary drainage for patients with malignant obstructive jaundice. Asian Pac J Cancer Prev, 15, 9391-4.

Xu C, Lv PH, Huang XE, et al (2015). Efficacy of Transarterial Chemoembolization Combined with Radiofrequency Ablation in Treatment of Hepatocellular Carcinoma. Asian Pac J Cancer Prev, 16, 6159-62.

Xu C, Lv PH, Huang XE, et al (2015). Radiofrequency Ablation for Liver Metastases after Transarterial Chemoembolization: A Systemic Analysis. Asian Pac J Cancer Prev, 16, 5101-6.

Yang L, Sun Y, Huang XE, et al (2015). Carcinoma microsatellite instability status as a predictor of benefit from fluorouracilbased adjuvant chemotherapy for stage II rectal cancer. Asian Pac J Cancer Prev, 16, 1545-51.

Zhou SB, Liu YC, Yin XX, et al (2015). Clinical observation of three dimensional conformal radiotherapy with tamoxifen in treatment of postoperative malignant glioma. Asian Pac J Cancer Prev, 16, 1743-5. 